\title{
The oil \& gas upstream cycle: Exploration activity
}

\author{
J. Craig and F. Quagliaroli \\ Eni - Exploration 83 Production Division \\ Via Emilia 1, 20097 San Donato Milanese (MI), Italy
}

\begin{abstract}
Summary. - Eni operates in all areas, from its traditional oil, gas and chemical businesses to renewable energy resources, through its business units and companies. Significant investments are also dedicated to research and development. Eni's organizational structure is oriented towards the oil \& gas core business, time and cost efficiency and the achievement of goals; an agile and effective organization in constant evolution, capable of responding promptly to the challenges that the scenario poses to the entire energy sector. Within the oil \& gas industry cycle, the upstream phase includes the exploration, which is the object of the present paper, the development, production and abandonment activities, whereas the midstream and downstream phases deal with the hydrocarbon transportation and trading to the refining and marketing. The exploration units manage Eni's exploration activities. Exploration is Eni's driving force, and it is this activity that in recent years has ensured, and will continue to ensure, the future organic growth of the company, with low costs and the flexibility to monetize quickly the results. The concluding section of the present paper will briefly review the future of the oil and gas industry in the context of the energy transition.
\end{abstract}

\section{Introduction}

Eni is an integrated energy company that operates in 73 countries worldwide thanks to the dedication of 33000 men and women. Eni's way of operating, based on operational excellence and focusing on health, safety and the protection of the environment, is aimed 


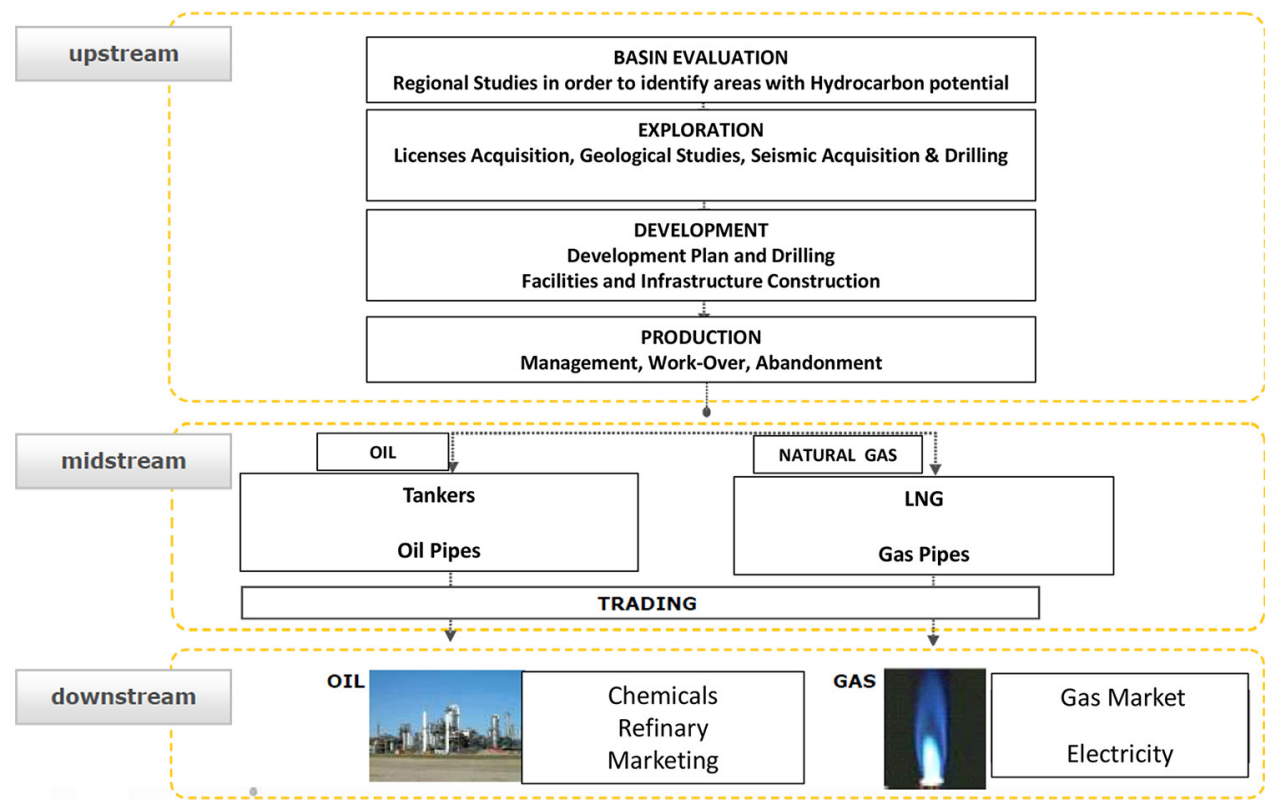

Fig. 1. - The oil \& gas cycle: Eni covering the entire chain.

at preventing and reducing operating risks. The company operates in all areas, from its traditional business but also in the renewable energy sector, through its business units and companies. Significant investments are also dedicated to research and development.

In Eni, the oil \& gas activities cover the entire oil and natural gas supply chain, as well as the production and marketing of electricity and chemical products. These activities are divided into upstream, midstream and downstream phases.

The upstream phase includes exploration, development, production and abandonment activities, whereas the midstream and downstream phases deal with hydrocarbon transportation and trading to refining and marketing (fig. 1).

The exploration units manage Eni's exploration activities. Each new exploration opportunity is assessed from the point of view of having, in the case of success, competitive projects that allow for a short time-to-market as well as low-cost development and operation and, in the case of "giant or super-giant" discoveries, being able to immediately monetize any excess volume by selling minority shareholdings, thus obtaining a cash flow advance (Eni's distinctive "dual exploration model").

Exploration is Eni's driving force, and it is this activity that in recent years has ensured, and will continue to ensure, the future organic growth of the company, with low costs and the flexibility to monetize quickly the results.

Development is the key activity that is carried out after discovery of a field and before production start-up, and it makes it possible to recover hydrocarbons through the creation of material assets (plants, wells, infrastructures etc.) and other works, whilst 
being constantly mindful of the local environmental and socio-economic context.

Once development is complete, production activities begin, the hydrocarbons are extracted from the field, processed in the plants and sent on to the market via pipelines or ships (midstream phase).

During its productive life, that might last decades, the field is constantly monitored. Work is carried out on the wells to optimize production and, in some cases, recovery projects are put in place, using the injection of gas or water to increase the quantity of recoverable hydrocarbons.

The downstream phase consists of the refining and marketing business. Eni is the major refinery operator in Italy and the Mediterranean and is the fourth largest in Europe. It is also the market leader in Italy both in the retail and in the wholesale business.

The refining of crude oil produces a number of products belonging to three main areas: petrol, diesel and combustible oils.

\section{1. - The exploration phase}

"Exploration" is a set of coordinated activities involving different integrated disciplines, sciences and technologies — not only geology/geophysics - aiming at discovering new oil and gas volumes that could be exploited in a "reasonable" future with an economic return.

To explore, one needs to understand and carefully map the present-day subsurface structure of an area, understand its evolution in time, locate the areas where hydrocarbons may be generated, locate and accurately map the structures in which they may be preserved, estimate their volumes, and evaluate the chances that our predictions are correct. To achieve these targets in the most efficient way, high-level skills and knowhow have to be employed using a powerful digitally integrated approach along with the support of dedicated R\&D projects.

1`1. Sedimentary basins and petroleum systems. - The exploration activity is carried out in sedimentary basins, which are regions of the Earth characterized by long-term subsidence allowing space for infilling of sediments. For hydrocarbon exploration, deep sedimentary basins are needed (usually over $2500 \mathrm{~m}$ of sediment thickness). For the generation and accumulation of the hydrocarbons the sedimentary basins must contain the five elements (fig. 2) of the so-called "petroleum system": Source Rocks, Reservoir, Carrier, Seal and Trap [1].

Source Rock: Sediments rich in organic matter (shales, marls, carbonates, coals) capable of generating hydrocarbons during thermal evolution (if deep enough to crack the organic matter). Oil vs. Gas generation depends on the quality of Source Rock and/or its thermal evolution. As an exception, biogas does not need thermal alteration.

Reservoir: Rocks, usually of sedimentary nature, with porosity and permeability capable of containing and flowing HCs during production.

Carrier: Permeable sediments and/or significant rock fractures (faults) allowing buoyancy flowing from Source Rock into Reservoir. 


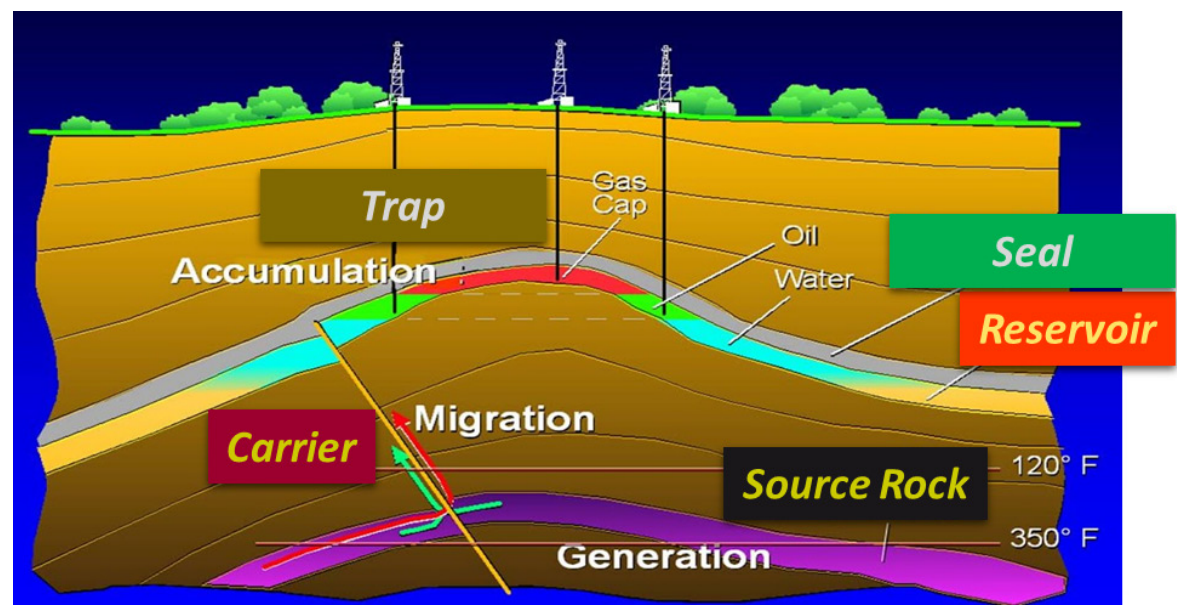

Fig. 2. - Within a sedimentary basin: the 5 elements of the petroleum system.

Seal: Rocks, usually of sedimentary nature, with no permeability, capable of creating a barrier above and around the reservoir.

Trap: Geometrical configuration of the Reservoir and Seal couplet allowing hydrocarbon accumulation.

\section{1`2. Hydrocarbon exploration methods}

1².1. Geological field campaign and remote sensing. Visible surface features such as oil seeps, natural gas seeps, pockmarks (underwater craters caused by escaping gas) provide basic evidence of hydrocarbon generation (be it shallow or deep in the Earth).

To find the hydrocarbons in the subsurface, most exploration depends on highly sophisticated technology to detect and determine the extent of these deposits using exploration geophysics. However, when it is possible, surface geological mapping and outcrop rock sampling carried out during a geological campaign are usually the first task in any reconnaissance project, allowing the geological and structural characteristics of the area (lithology, sequence thickness, structural configuration) to be defined. The collected rock samples are then analyzed in laboratories providing useful data such as age, petrophysical parameters (i.e., porosity and permeability) and, for potential source rocks, total carbon content, quality of organic matter and thermal maturity.

Surface geological investigation can be coupled with Satellite Remote Sensing data acquisition which can provide a geomorphological characterization of the study area from accurate elevation data (Digital Elevation Model (DEM)), morphological features (dunes, rivers, outcrops, etc.) to main rock-type discrimination. Remote sensing can also provide information about oil slick or seepage presence on the sea surface which could confirm the existence of a "working" petroleum generation system. 


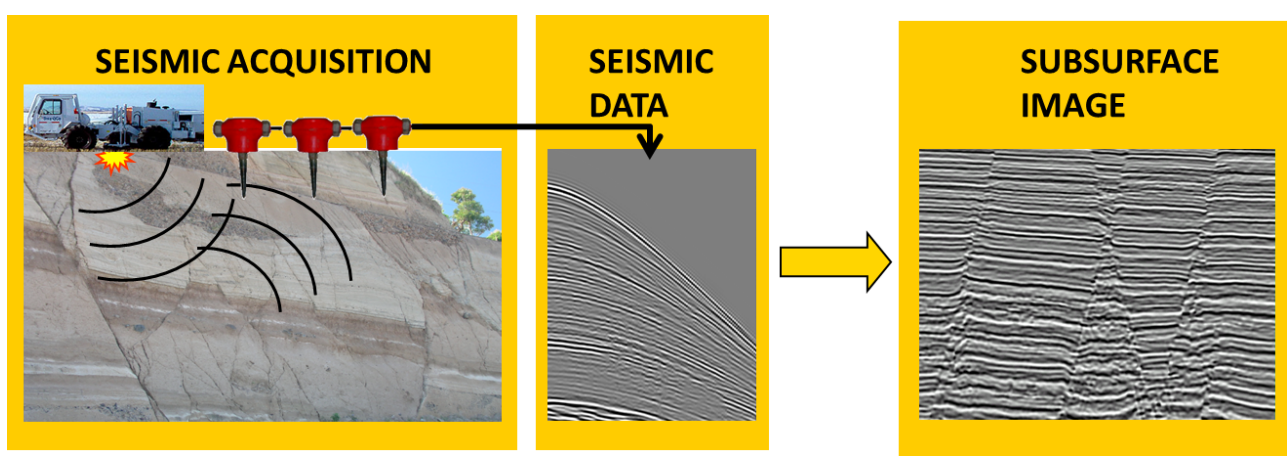

Fig. 3. - From seismic acquisition to subsurface image.

1`2.2. Geophysical acquisitions: gravity and magnetic data. After the aforementioned initial studies, basins thought to contain hydrocarbons are initially subjected to gravity and magnetic surveys in order to detect those areas and geological features in the subsurface which are considered significant for the accumulation of hydrocarbons.

Gravity and magnetic surveys can detect anomalies in the gravity and magnetic field of the Earth. Basically, these anomalies can be associated to variations in specific physical properties of rocks (density or magnetic susceptibility) and after data processing, the interpretations can tell us about basin shape and extent, structural trends, fault locations (essentially, gravimetry) and depth to basement, basement lineation, presence of igneous bodies (essentially, magnetics).

1·2.3. Geophysical acquisitions: seismic data. Areas or geological features of interest based on the gravimetric and magnetic studies are subjected to more detailed investigation through seismic surveys. Seismic surveying involves making two- or threedimensional images of the Earth by analyzing the pattern of propagation of sound waves through the subsurface. These images provide information about the subsurface structures. The method consists of using sound waves that are transmitted into subsurface where they propagate through the rock mass and undergo reflection and refraction at certain geological discontinuities. The reflected waves, which return to the surface, are recorded by sensors.

For surveying on land the seismic waves used are generated by vibrating the ground surface artificially using either buried explosive drilled into ground or, more often, by a kind of sweep-type vibrator (Vibroseis). The sensors, which record the reflected waves, are called geophones (fig. 3). Offshore, waves are generated by compressional air guns that shoot pulses of air into water. The sensors (hydrophones) contained in a tube (streamer), are towed behind the vessel to record the reflected waves.

The seismic waves travel at different velocities depending on the type or density of rock layers through which they pass. Return time, the interval in which the signal is returned, when converted into depth, provides an image of the subsurface structures. The 


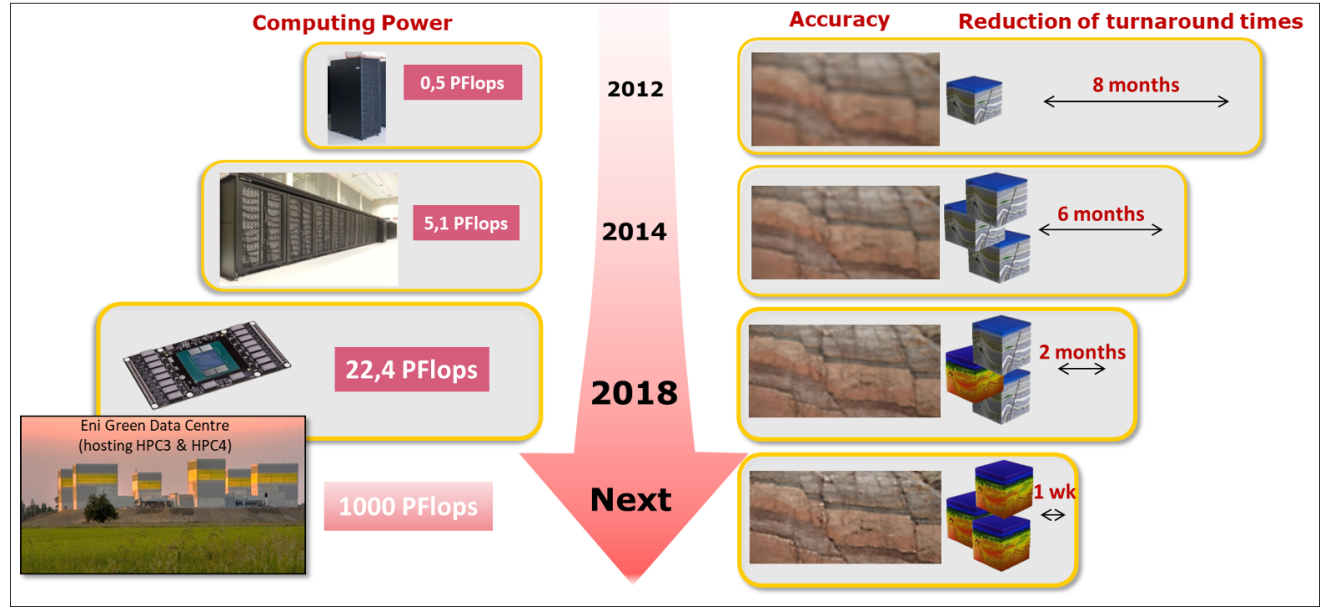

Fig. 4. - Digital simplification of geo-complexity.

results of a seismic survey can indicate the presence of possible hydrocarbon traps which eventually would be the target of drilling. The work necessary to obtain a subsurface image starting from the raw seismic acquisition data is called seismic data processing. The seismic processing sequence designed to achieve the most accurate and interpretable image of the subsurface consists of several individual steps. The number of steps, the order in which they are applied and the parameters used for each program vary from area to area, from dataset to dataset, and from processor to processor.

The amount of computer processing needed to transform the raw seismic data into coherent views of the underlying strata is massive and the petroleum industry has always provided good customers for High Performance Computers (HPC).

In Eni the HPC4 supercomputer has a peak performance of 18.6 PetaFlop/s which, combined with the supercomputing system already in operation (HPC3), increases Eni's computational peak capacity to 22.4 PetaFlop/s (fig. 4).

1 2.4. Geological and geophysical (G\&G) studies. Multi-disciplinary and integrated geological and geophysical (G\&G) studies are a necessary step in assessing the petroleum potential of an area before drilling a well and to evaluate the geological risk of finding a hydrocarbon accumulation. Data from previous exploration campaigns, if the area has already been explored, is integrated with the newly acquired geological and geophysical surveys. The most common geological studies are the biostratigraphy and sedimentology characterizations that define age and the depositional environment of the rocks. Geochemical analyses of the presumed source rock, along with the integration of the above G\&G studies, can help identify areas of hydrocarbon generation and expulsion (Kitchen) and their timing (Petroleum System Modelling "PSM"). Moreover, if an accurate subsurface image is available, the PSM can provide useful information about hydrocarbon migration pathways and trap charging (fig. 5). 


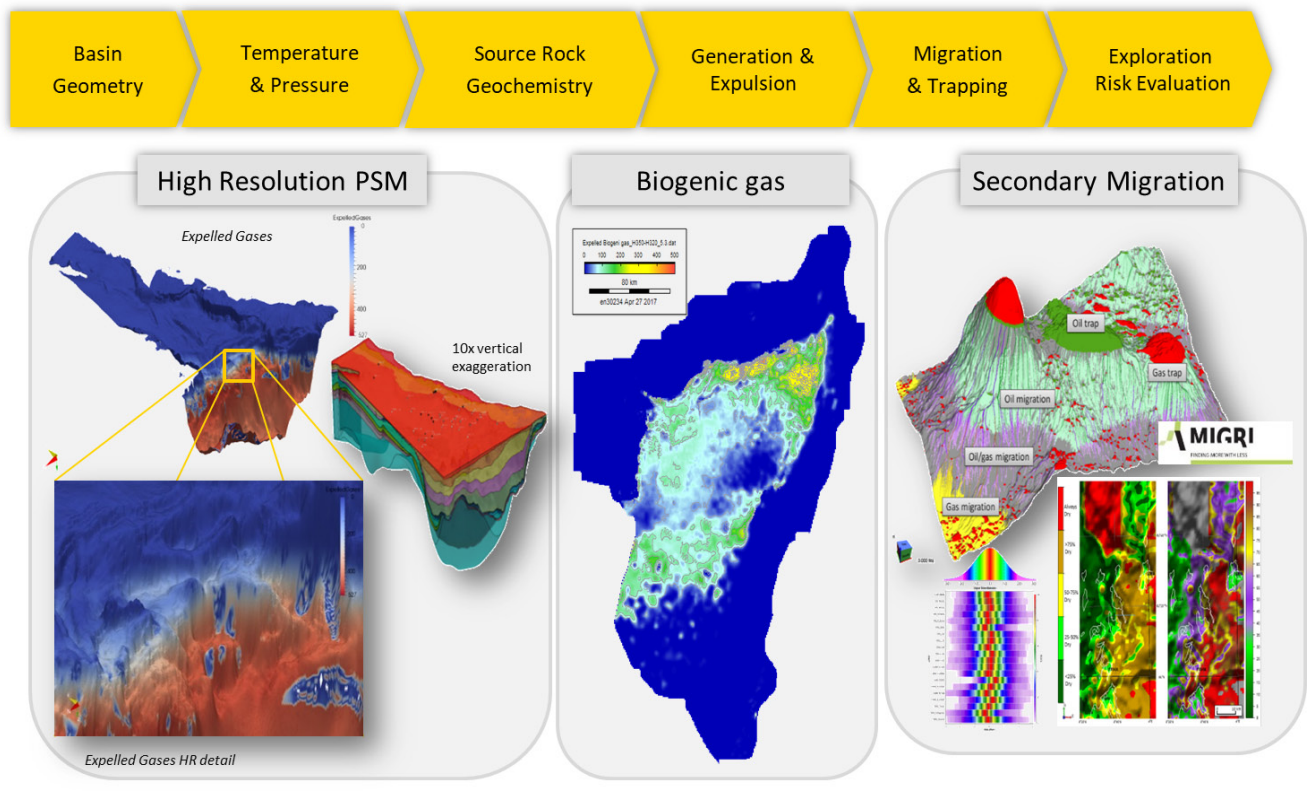

Fig. 5. - G\&G studies: Petroleum System Modelling (PSM).

Geophysical studies are elaborations, often based on the extraction of the seismic attributes of the processed data, that sometimes require additional processing sequences. Essentially, most of these studies are aimed at identifying the presence and location of porous zones or the presence of hydrocarbons in the interpreted reservoir (wavelet amplitude and polarity anomalies). The observed variation of the wavelet amplitude with respect to angle of incidence may even indicate the nature of pore-fluids (Amplitude vs. Offset (AVO)).

1`2.5. Prospect generation. The final processed seismic data, usually displayed in maps or sections, allows the accurate mapping of the subsurface geological features, both depositional and structural. Through the mapping and the G\&G studies mentioned above, it is possible to identify the most promising areas in which hydrocarbons are predicted to exist. A "prospect" is commonly an identifiable structural or stratigraphic closure (trap) or a seismic amplitude anomaly that could be recommended by explorationists for the drilling of a well (fig. 6).

In summary, justification for drilling a prospect is made by assembling evidence for an active petroleum system, a reasonable probability of encountering reservoir-quality rock, a trap of sufficient size, adequate sealing rock, and appropriate conditions for generation and migration of hydrocarbons to fill the trap. Volumes of hydrocarbons contained in the prospect are then calculated using a probabilistic approach and dedicated software. Besides the volumetric computation for each prospect, it is important to define the chance, or probability, of geologic success, i.e. the probability of finding mobile hydrocarbons 


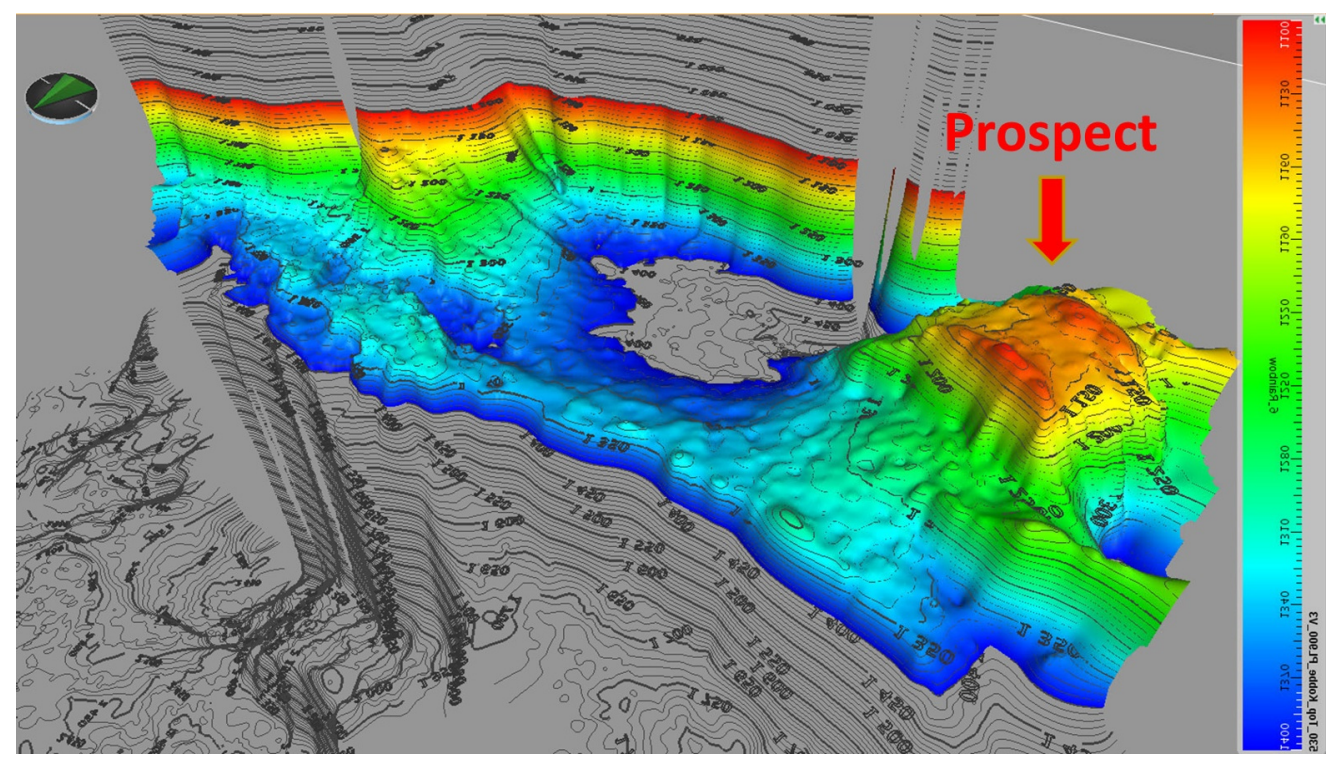

Fig. 6. - Interpreted subsurface image pointing out a trap or closure (prospect).

in the prospect given the assumed geological model. Probability of Success (POS) is commonly obtained by multiplying probability to have in the area the essential geologic elements of the Petroleum System (Source Rock, Reservoir, Carrier, Seal and Trap). POS of less than $15 \%$ characterizes high risk prospects, whereas POS of greater than $35-40 \%$ is common for low risk prospects. Combinations of the hydrocarbon volumes and their POS gives a prospect ranking of the area and these figures are essential input data for the economic assessments, together with the expected exploration and production costs, oil price scenarios and the contractual terms of the permit.

1'2.6. Well drilling. Finally, when a prospect has been identified and evaluated and passes the oil company's selection criteria, an exploration well is drilled in an attempt to conclusively determine the presence or absence of oil or gas.

Oil (or gas) well drilling is a complex operation and the drilling industry engages the services of personnel and a complicated array of machinery and materials to drill an oil/gas well to depths even greater than 6000 meters. The drilling industry has seen technological progress, however, these advances have not changed the fact that, besides the use of complicated machinery, successful drilling is a result of tremendous team effort. Numerous personnel from the operating company and several service companies work together to drill and complete an oil/gas well.

The drilling phase is an expensive, high-risk operation. Offshore (fig. 7) and remote area exploration is generally only undertaken by very large corporations or national governments. Typical shallow shelf oil wells (e.g., North Sea) cost US\$10-30 million, 


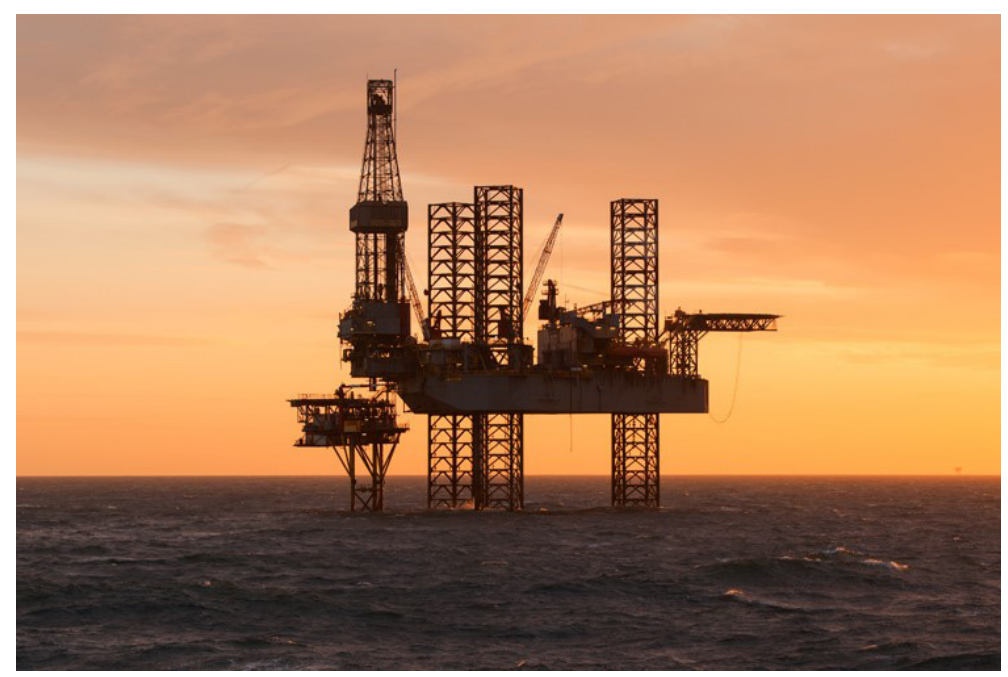

Fig. 7. - Offshore drilling rig.

while deep water wells can cost up to US $\$ 100$ million or even more. Hundreds of smaller companies search for onshore hydrocarbon deposits worldwide, with some wells costing as little as US $\$ 500000$.

Rotary drilling is the most efficient technology applied in the oil and gas industry. It is a drilling technology that relies on continuous circular rotation of the bit to break rocks (cuttings), while drilling fluids circulate through the bit and up the wellbore to the surface, making it possible to drill the well safely and efficiently.

Many operations are carried out during drilling to determine the nature of the sequences crossed and the presence of hydrocarbons. Among these, the most important are the acquisition of the so-called electrical and radioactive logs (geophysical surveys in the well), coring and tests to ascertain the presence and the chemical-physical quality (composition and pressure) of any hydrocarbons.

After a successful exploration well, before proceeding to the development and production phase of the discovery, additional wells are usually drilled to allow an accurate delineation of the extension of the field (Appraisal or Outpost wells). All the newly acquired data are again elaborated through additional G\&G studies (fig. 8) which allow the subsurface geology and volumes of the hydrocarbon-bearing reservoir to be understood in great detail. All these relevant outcomes are crucial to planning the development and production phase correctly, which is the most expensive part of the upstream cycle (hundreds million to billion US\$), in order to achieve a fast time-to-market and to be able to immediately monetize any excess volume by selling minority shareholdings, thus obtaining cash flow in advance (the "dual exploration model"). 


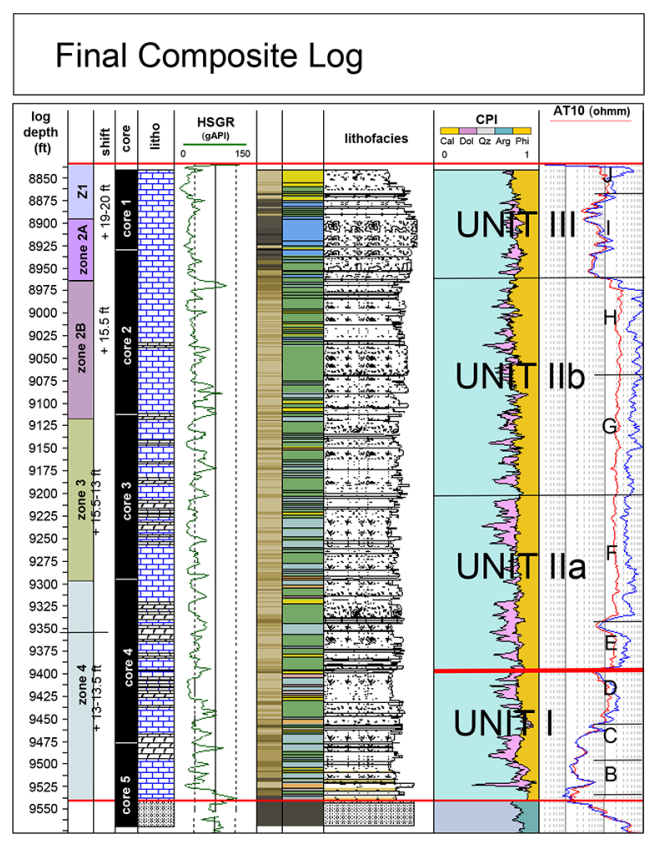

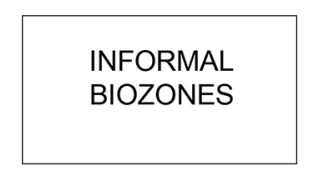

"Miolepidocyclina panamensis "

“Miogypsina

(Miogypsinita)

cf. staufferi “

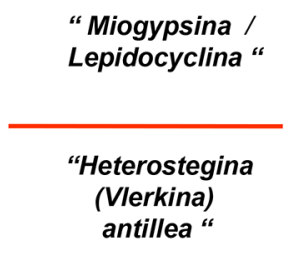

"Miogypsina / Lepidocyclina "

(Vlerkina)

antillea "

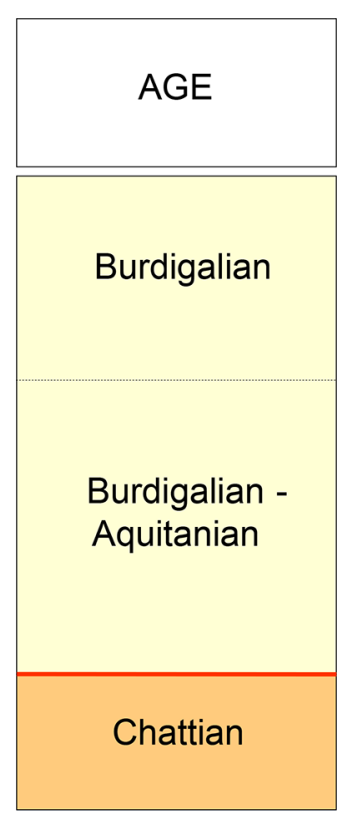

Fig. 8. - Integrated biostratigraphic study of a well, with the age of sediments encountered along the borehole through microfossil recognition.

\section{2. - Unconventional resources}

While different definitions have been proposed to classify unconventional resources, we consider them as subsurface hydrocarbon resources found in reservoirs which have geological characteristics and locations that are different to those in which oil and gas are usually produced. These geological formations include tight gas sandstones, oil or tar sands, heavy oil, gas shales, coalbed methane, oil shales, gas hydrates, and other lowpermeability tight formations. Among them, gas and oil shales and coalbed methane are typically source-rock reservoirs (fig. 9).

$2 \cdot 1$. Pros and cons of the unconventional exploitation. - There are public concerns over the development and production of unconventional resources, since it is generally more difficult than for conventional sources.

The extraction of shale gas, for instance, requires the drilling of many wells and using techniques such as hydraulic fracturing, also called "fracking". Fracking is one of the more recent methods of natural gas and oil extraction. It involves drilling into deposits of shale gas and oil, for which the usual methods of extraction are not efficient, and injecting high-pressured water into the rocks that contain the hydrocarbons. This water, mixed with sand and a special mixture of chemicals causes the rock to break. The breaks or "fissures" in the rock are then held open by the sand and chemicals that have been added. Through these fissures, the gas or oil then escape into the well. Once at the surface, the hydrocarbons are stored, ready to be processed and transported. 


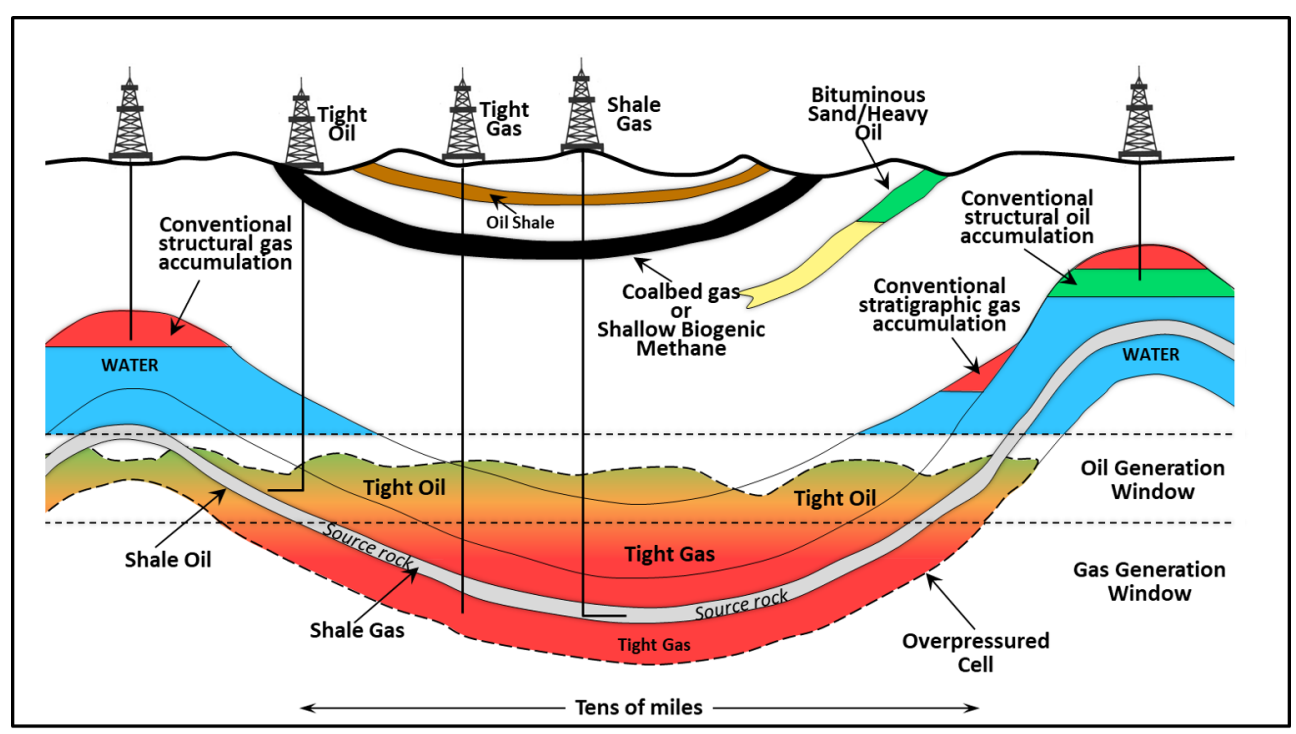

Fig. 9. - Conventional and unconventional targets.

However, recently there have been many arguments against using fracking to get access to the natural deposits of fossil fuels, beside the fact that the high costs of unconventional exploitation make it only economic with high oil prices. There are also environmental issues that need to be taken into account, among which are the elevated number of wells for the exploitation compared to the conventional exploitation, the visual impact, noise and the huge quantity of water needed. Another issue is the local seismicity that could be induced in the area.

Without doubt, the main unconventional resource is shale gas. Many industry officials and observers have suggested that shale gas might be a "game changer" in the global economy, altering the traditional division of the world between energy-rich supplier countries and energy-poor consumer countries. In an assessment of 14 shale gas-bearing regions outside the United States, the EIA (Unites States Energy Information Administration) has estimated that the shale gas resources of those regions (comprising 32 countries) plus the shale gas resources of the United States have increased the world's technically recoverable gas resources by more than $40 \%$ [2]. Many of these newly assessed resources are in countries that have not been major producers of conventional natural gas, raising the attractive possibility that some countries may be able to pursue economic growth while also reducing their dependence on foreign energy sources. For EIA, the estimated technically recoverable gas from the unconventional shale gas is 6622 Tef in 48 basins contained in 32 countries (fig. 10).

However, the strategy of the Eni is not to explore for, or produce, unconventional oil and gas, in contrast to its competitors and other major companies. 


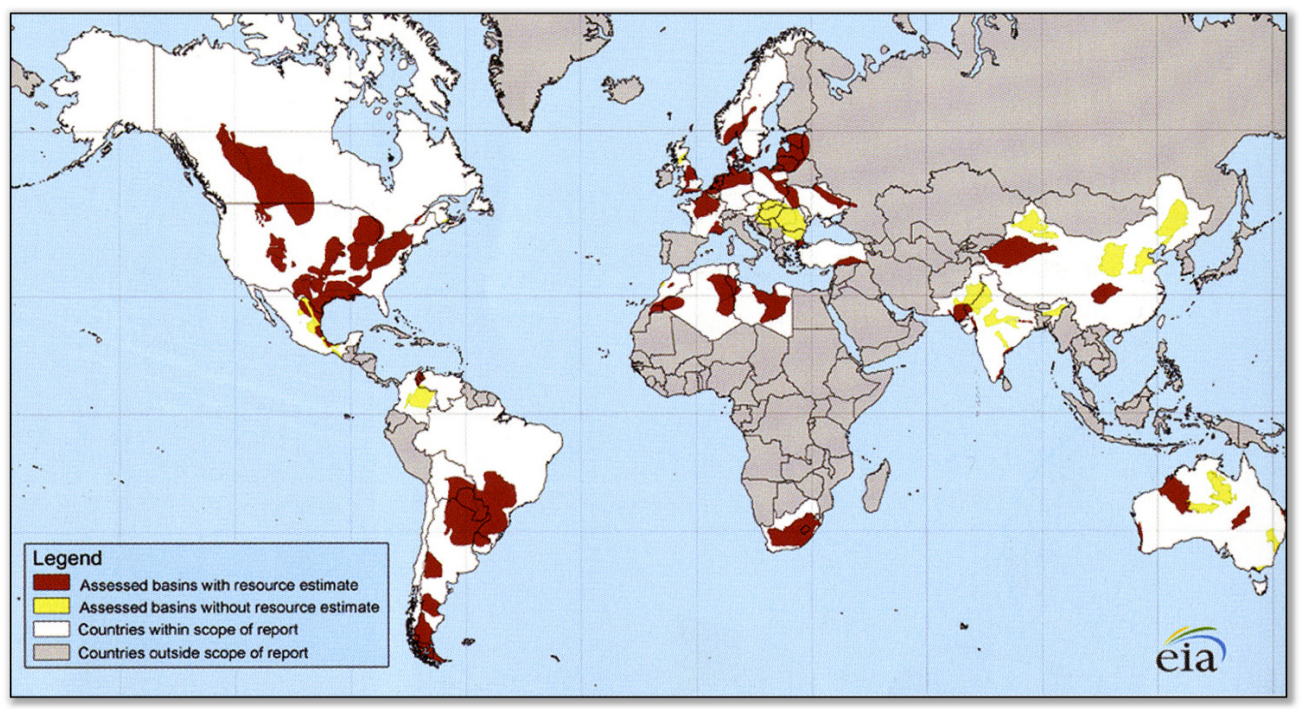

Fig. 10. - Unconventional basins in the world (from U.S. EIA, 2014).

\section{3. - The future of oil and gas industry}

The world currently consumes about 100 million barrels oil a day. While projects are planned for an increased use of renewable energy resources, improved energy efficiency and a shift toward electric vehicles, oil will continue to meet rising demand for petrochemicals and fuel transportation (fig. 11).

Moreover, natural gas demand will grow as countries seek to lower greenhouse gas emissions by displacing coal for heating and power generation. Natural gas is cost effec-
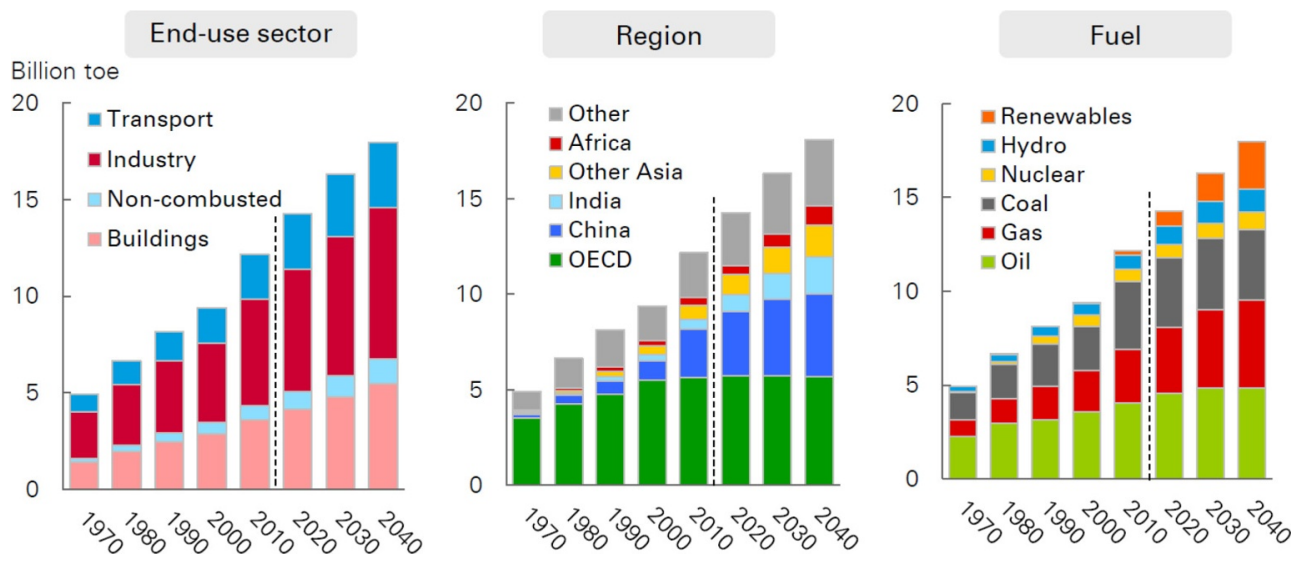

Fig. 11. - Primary energy demand (from [3]). 


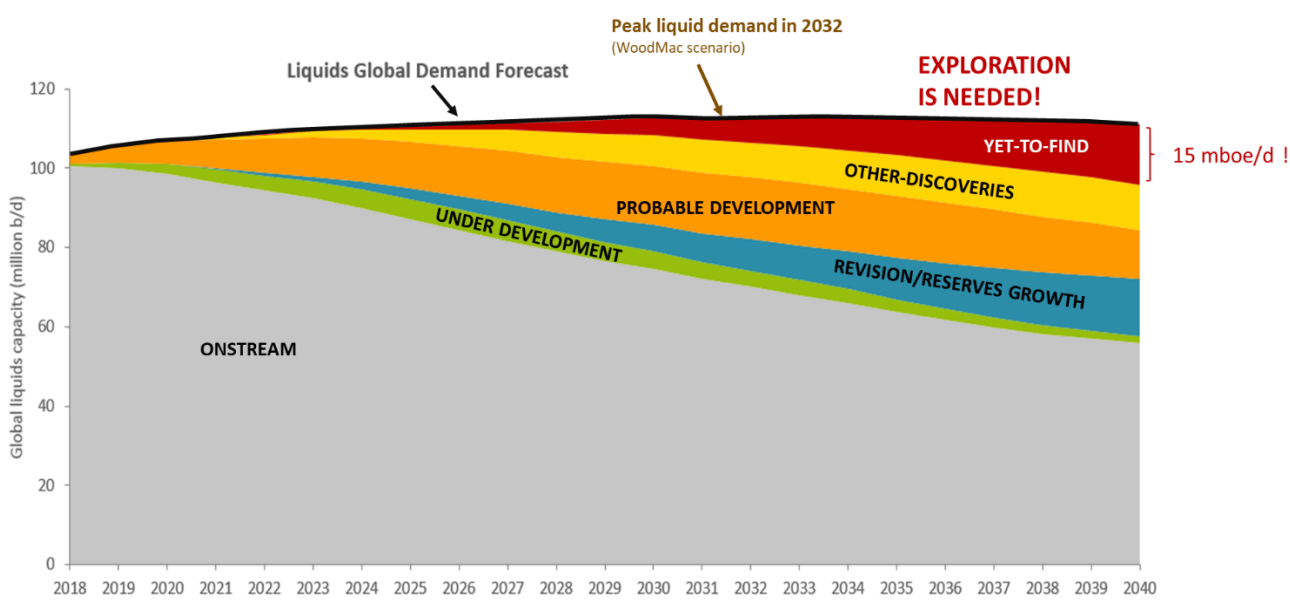

Fig. 12. - The need of new discoveries (from [3]).

tive, abundant and reliable while producing 40 to $65 \%$ fewer emission than coal. As a result, new discoveries are required to fill the future needs of fossil fuels (fig. 12).

Nevertheless, the oil and gas industry is facing a particularly challenging set of obstacles, including a volatile oil price and a poor public image. The negative image of the oil and gas industry (incidents causing pollution, accidents, greenhouse effects, fracking techniques are wrongly considered as a routine part all the oil and gas operations by much of the general public) makes it challenging for the companies operating in the oil
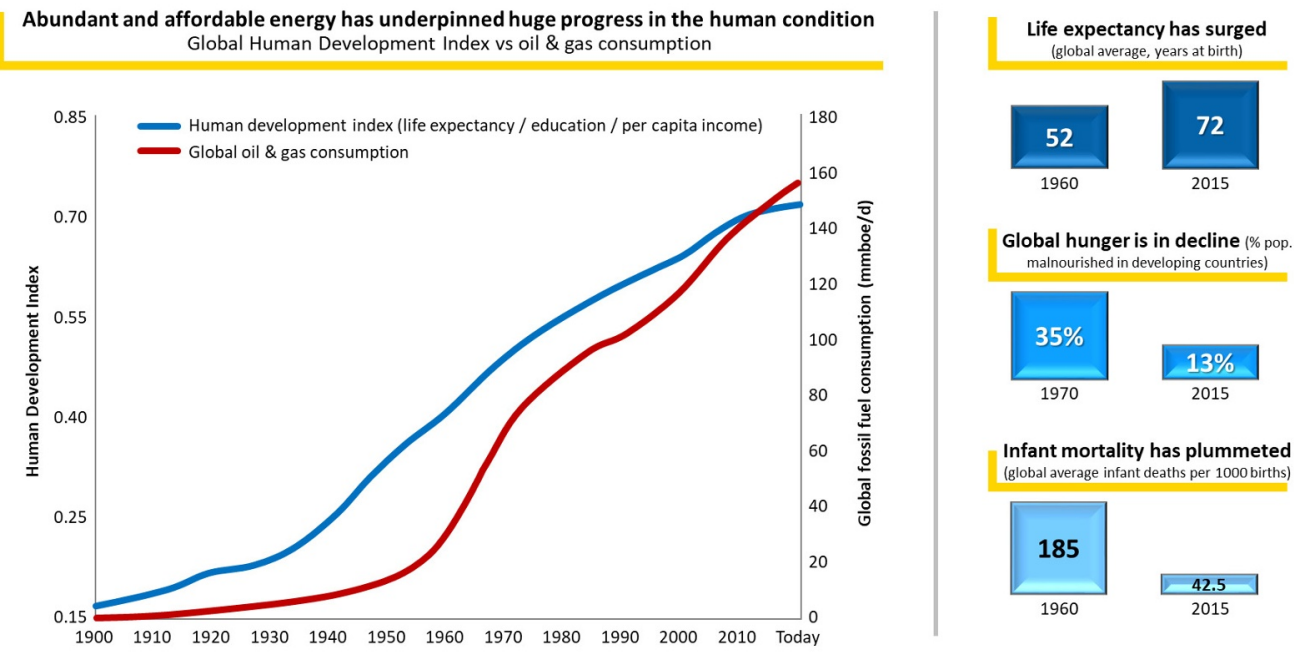

Fig. 13. - Global human development index vs. oil and gas consumption (from United Nations Development Programme and Eni S.p.A.). 
and gas sector to recruit talented staff as well as limiting their ability to raise capital from institutional investors who often perceive the business as expensive and risky. The lack of public trust in the industry complicates project development and jeopardizes government approval of major infrastructure projects.

However, there is currently no feasible alternative to some vital petroleum products, including petrochemical and lubricants. The industry is not dying, but is changing and it must continue to do so. The world needs more investment in research and development on reducing the impact of energy use. That includes creating cleaner energy sources and improving the performance of hydrocarbons to reduce their environmental impact. Reducing carbon emissions is high on the list of priorities of all energy companies' in what will surely be a different future for the hydrocarbon-based part of their business.

Finally, it is worth mentioning that since the industrial revolution, oil and natural gas have played a fundamental role in transforming economic and technical aspects of everyday life for the majority of the world's population, not least through the provision of abundant and affordable energy, resulting in a consequent sharp increase in quality of life and life expectancy (fig. 13).

\section{REFERENCES}

[1] ENI Glossario dell'Industria Petrolifera (GECA spa) 2007.

[2] U.S. EIA Annual Energy Outlook, 2014 edition (2014).

[3] BP Energy Outlook, 2018 edition (2018). 